Type of the Paper (Article, Review, Communication, etc.)

\title{
Tashi-Bot: A Intelligent Personal Assistant for Users in an Edu- cational Institution
}

\author{
Henriquez Carlos ${ }^{1}$, Sánchez-Torres German ${ }^{1}$ and Salcedo Dixon 2,* \\ 1 Facultad de Ingeniería, Universidad del Magdalena, Santa Marta, Colombia. 1; chenriquezm@unimagda- \\ lena.edu.co (H.C.); gsanchez@unimagdalena.edu.co (S.G.) \\ 2 Computer Science and Electronics Department, Universidad de la Costa; dsalcedo2@cuc.edu.co (S.D.) \\ * Correspondence: dsalcedo2@cuc.edu.co
}

\begin{abstract}
The number of AI applications in education is growing every day. One recent AI application in the educational sector is Chatbot technology, which is used to support teaching and administrative tasks. This document presents the design and implementation of a Chatbot called TashiBot that helps applicants and university students to obtain information from an educational institution about certain academic and administrative processes. Among these are processes related to well-being, tuition, costs, admission, and other services. In order to design the Chatbot, an analysis of the state of the art, methodologies, and suitable tools was carried out, and a survey was conducted to discover the needs of users and their preferences in the use of a Chatbot for this specific purpose. Tashi-Bot was implemented on the SnatchBot platform and later deployed on a Telegram channel. In its evaluation, a final survey was carried out to check on the satisfaction of the users. The results suggest that Tashi-Bot could help applicants and university students to find information on academic and administrative processes with great certainty and without the need for human interaction. Tashi-Bot can be found at: https://web.telegram.org/\#/im?p=@TashiE_Bot..
\end{abstract}

Keywords: Chatbot technology; Artificial intelligence; Computer Science Education

\section{Introduction}

Nowadays, customer service is one of the most important components that must be addressed by a company. The quality of a customer support system depends on the information it provides, the services, and the different channels that it offers for serving its customers and thus achieving high satisfaction [1]. Currently, emerging technologies make it possible to improve customer service by, for example, creating artifacts with the ability to carry out certain processes and tasks automatically. These technologies have their origin in the field of AI, which allows a machine to be created with the ability to simulate intelligence, process images or videos, predict events, and understand human language [2][3].

$\mathrm{AI}$ as a general concept has been worked on for many years and has given way to the emergence of new specialized disciplines for each smart task. Such is the case with the discipline of Natural Language Processing which is oriented to facilitating the development of applications that help understand human mechanisms related to language [4]. Within NLP, there is a branch dedicated to creating intelligent programs with the ability to interact with humans using text or voice, offering quick responses based on the input information. This branch deals with Chatbots, computer systems capable of producing texts by themselves in such a way that when read by humans they make sense [5].

Although Chatbot technology has matured over time, it is still necessary to investigate how to add value appropriately to the different ways of using the technology to solve problems [6]. Currently, Chatbots are mainly used for customer services, online purchases, payment management, information delivery, personal assistance, entertainment, and e-commerce [7][8][9][10]. The most common Chatbot model is a robot capable of simulating a conversation with a person and performing a series of tasks on its own without 
the help of a human being; examples of the tasks are making a restaurant reservation, marking a date on the calendar, or collecting and displaying information to users [11].

A Chatbot is a software tool that interacts with users on a certain topic or in a specific domain naturally and conversationally using text and voice [12]. The purpose of a Chatbot system is to simulate a human conversation; Chatbot architecture integrates a language model and computational algorithms to emulate informal communication between a human user and a computer using natural language [13]. The fundamental core of a Chatbot is NLU, which aims to extract the context and meaning of user input in natural language, which may be unstructured, and respond appropriately according to the user's intention. The user's intent is then identified, and specific entities are extracted from the domain. More specifically, an intent represents a mapping between the user's input and the action that the Chatbot should take. Actions correspond to the steps that the Chatbot will take when specific intents are triggered by the user's input, which may have parameters to specify detailed information about it [14].

Chatbots have been created for the educational sector, in different ways particularly: as a teaching and learning strategy based on games [15], to improve the learning experience of students in higher education [16], to teach English [17], and as an intelligent assistant in a higher education environment [18]. Our proposal is framed in this last application, as we propose a method to allow educational institutions to answer questions on academic administration posed by their students, without having a person in charge.

The objective of this article is to present the design and implementation process of a Chatbot called Tashi-Bot, which helps applicants and university students to find out about certain academic and administrative processes of their educational institution. In addition, our proposal can offer them other 24/7 service channels that reduce labor costs, reorganize established functions, and create new innovative services. Among the process-related information managed by Tashi is information on enrollment, careers, costs, admission, and other services. The focus of this work is to understand what type of information and services are best accessed through a Chatbot, and how the personality of the assistant influences the user's experience and interaction.

This article was written as the result of a research project at the seedbed level with the participation of the research seedbed "Natural Language Generation" of the Magdalena University, Colombia. The rest of this paper is structured as follows. In section 2 we describe the methodology used for the development of this study, in section 3 we present the implementation and results of our Tashi-Bot, and finally, our conclusions are in section

\section{Methodology}

For the Chatbot design, an analysis of the state of the art, methodologies, and suitable tools was carried out, together with a survey to discover users' needs and their inclination to use a Chatbot for this specific purpose. After studying how to build a Chatbot [19][20][21][22], an initial design with the following phases was proposed:

\subsection{Needs and content analysis}

- Define the subject: In this stage, we define the type of Chatbot that is going to be built and the possible topics to work with. In this part, we survey all possible customer users;

- Determine the contents: After the initial inquiries, and as a result of carrying out a survey, we prioritize the contents according to the highest percentage obtained for the perceived importance of each subject;

- Define the requirements: In this stage, we define the general requirements of the Chatbot: what it is going to do, how it is going to be navigated, the types of messages it will transmit, and the target population. The correct definition of the requirements allows us to develop a product of good quality and performance that satisfies the needs of the users.

\subsection{Chatbot design}


- $\quad$ Establish personality and tone: Chatbots and virtual assistants usually have names. When consumers interact with a Chatbot, their brains tend to believe that they are having a conversation with another human being. At this stage, our Chatbot's name, age, traits, and other personal characteristics are determined according to the target population;

- Define the scheme: At this stage, conversational app features are defined. These include possible routes and definitions of the use cases according to the objectives;

- Determine the tool: At this stage, the tool or framework to be used to build the Chatbot is selected, considering the population needs identified in the previous phase.

\subsection{Chatbot design}

- Component implementation: Here the Chatbot construction begins, based on the previously defined requirements, and use cases. We begin by developing each module, using an iterative-incremental process that involves prioritizing requirements and prototype deliveries in a given time range;

- Component unit tests: At this stage, each component is tested using multiple text inputs and their possible responses. Here training must be carried out based on the benefits of each tool. There are Chatbot platforms that provide automatic machine learning models and training tools.

\subsection{Test and deployment}

- Determine the deployment channel: At this stage, the best channel option is selected in order to test the Chatbot. The options range from a standalone application to the web or a specific social network;

- $\quad$ Beta test: This is the test that is made with a selected group of users, where, after the application is tested, a survey is carried out to measure the users' satisfaction.

- Operational test: Finally, after the beta test and using the feedback on satisfaction, adjustments are made to the Chatbot according to the common comments of the users. At this stage, the Chatbot is released for other users of the institution. 


\section{Results}

\subsection{Chatbot theme and requirements}

Following the proposed methodology, an analysis and inquiry of the needs of educational institutions was carried out. In this part, we administered a survey to three groups of students (90 in total). The main questions and purposes are described in Table 1. The students' responses are shown in Figure 1.

Table 1. Inquiries to a group of potential users.

\begin{tabular}{|c|c|}
\hline Question & Purpose \\
\hline 1. Gender & $\begin{array}{c}\text { Design the Bot's personality according to } \\
\text { the students' gender }\end{array}$ \\
\hline 2. Age & $\begin{array}{c}\text { Design the Bot's personality according to } \\
\text { the age range }\end{array}$ \\
\hline $\begin{array}{l}\text { 3. As a student, have you ever needed } \\
\text { information on a process related to the } \\
\text { university community (welfare, registra- } \\
\text { tion, enrollment, teachers, etc.)? }\end{array}$ & $\begin{array}{l}\text { Discover what kind of information the Bot } \\
\text { should have }\end{array}$ \\
\hline $\begin{array}{l}\text { 4. From which department or section } \\
\text { have you requested information? }\end{array}$ & $\begin{array}{c}\text { Classify the departments from which the } \\
\text { information was sought, to establish con- } \\
\text { tent }\end{array}$ \\
\hline $\begin{array}{l}\text { 5. Have you heard of virtual assistants } \\
\text { or Chatbots? }\end{array}$ & Discover whether Chatbots are familiar \\
\hline $\begin{array}{l}\text { 6. Would you like a virtual assistant or } \\
\text { Chatbot to help you find information } \\
\text { more easily at the university? }\end{array}$ & $\begin{array}{l}\text { Discover the possible level of use of the } \\
\text { Chatbot by users }\end{array}$ \\
\hline
\end{tabular}
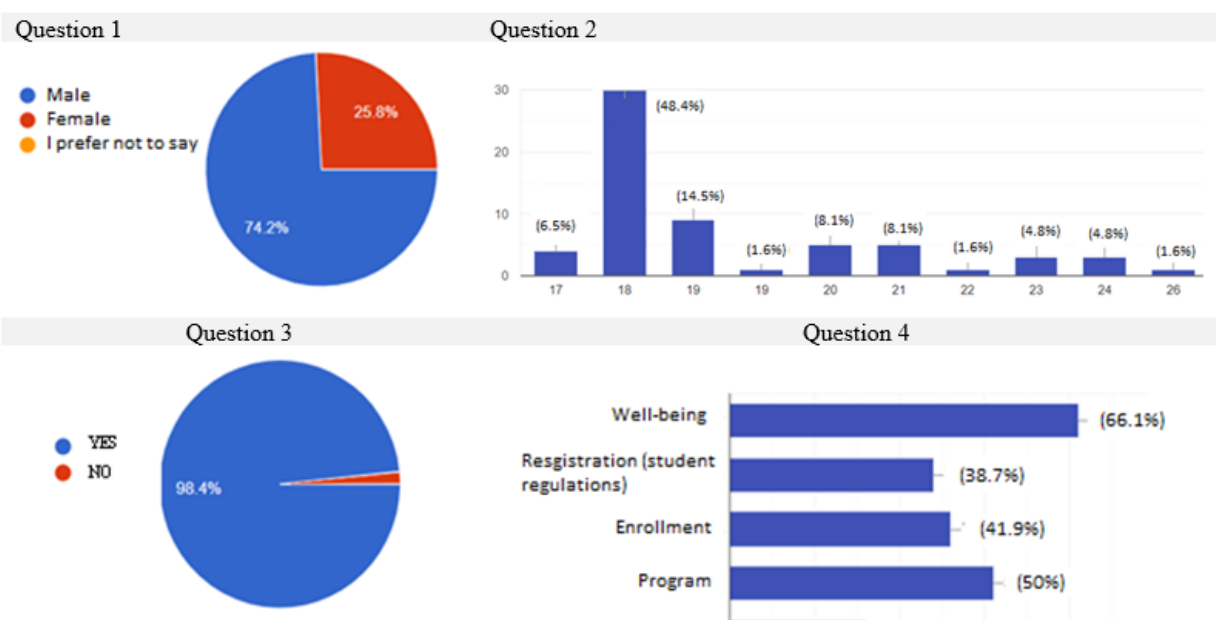

Question 4

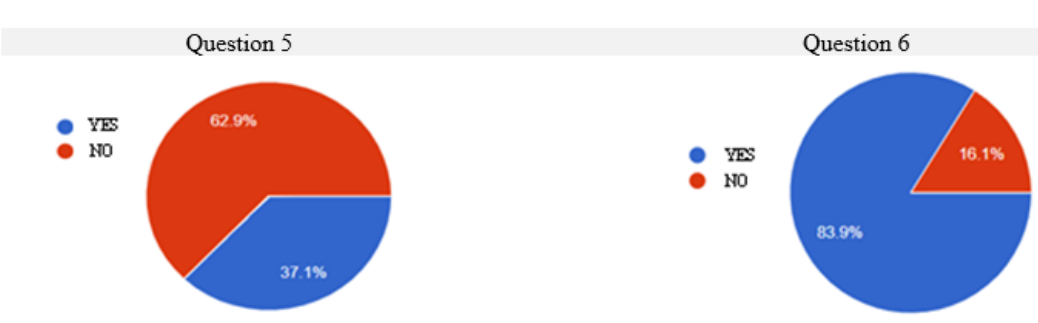

Figure 1. Initial investigation result of end users.

The results of the survey placed before us a mostly male population $(74.2 \%)$, aged between 17 and 26 years old, with the potential users aged under 19 years old. This target 
population does not know the term Chatbot (62.9\%) but is willing to receive simple information regarding the university using this technology (83.95\%). Additionally, using the survey results, we took the first three topics for which the students had requested more information (well-being, majors, and enrollment) for working with the Bot. The topics to be dealt with in each area were then defined as shown in Table 2.

Table 2. Prioritized areas with the different topics to be dealt with by the Chatbot.

\begin{tabular}{cc}
\hline Area & Topics to discuss \\
\hline Well-being & Description, services, work team, location. \\
Enrollment & Tuition cost, schedules. \\
Majors & $\begin{array}{c}\text { Existing majors, faculties, description, objectives, cur- } \\
\text { riculum, costs, and services. }\end{array}$ \\
\hline
\end{tabular}

After defining the areas and themes, the Chatbot's requirements, both functional and non-functional, were defined as follows:

Functional requirements:

- Allow the user to ask questions regarding the theme;

- Offer feedback when the user does not understand any questions;

- Show buttons for easy access to information;

- Allow the user to measure his or her satisfaction quantitatively;

- Allow easy navigation between themes;

- Match similar phrases or words with different answers;

- Identify usernames to store their satisfaction.

Non-functional requirements:

- Combine text and images to achieve a better interaction with the user;

- Have a design that suits the target population;

- Handle bright colors and minimal text;

- Allow navigation to external sites to complement the given information;

- Allow deployment on different websites. 


\subsection{Chatbot design}

Based on the target population, the Chatbot's personality, skin color, characteristics, and graphic expressions were established (Figure 2).

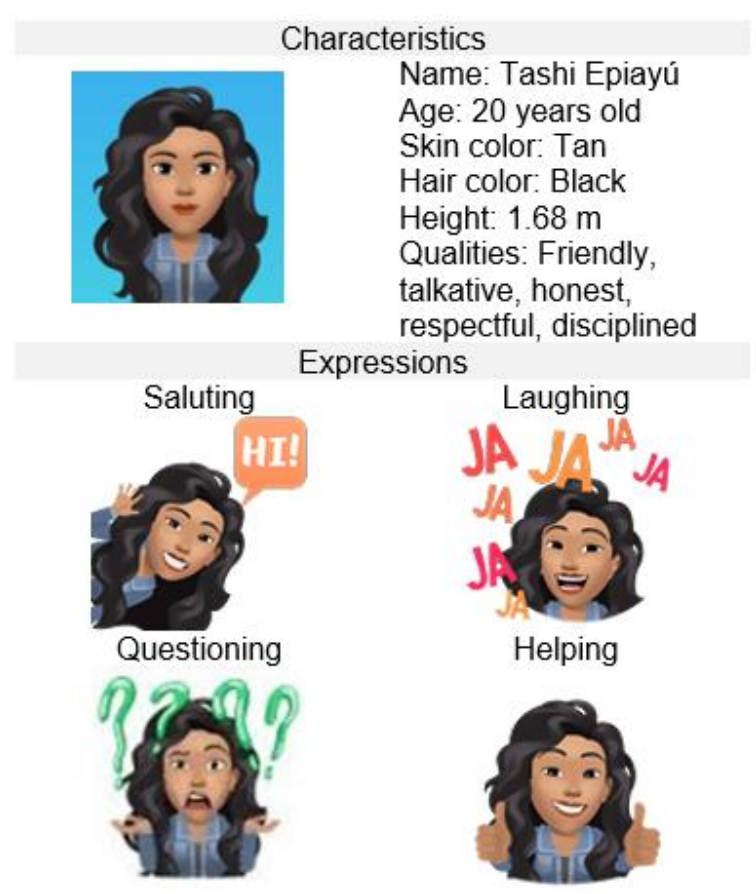

Figure 2. Tashi-Bot characteristics.

Table 3 presents the different tools available for building Chatbot virtual assistants. The different platforms were analyzed, considering the common criteria among them. For the selection decision, weightier criteria were considered, such as whether access to the tool was free, NLP management, language management, scheme definition, and deployment in social networks. The two platforms initially selected were DialogFlow [23] and SnatchBot [24], which fully met all the established requirements, including deployment in social networks and a robust engine for NLP. Finally, and after prototyping each tool, the SnatchBot tool was selected because of its intuitive interface (usability) for the creation of expressions, intentions, and entities, and the verification of the Bot's flow through diagrams.

With the selected tool, the general scheme for the Bot is defined on the basis of the introduced theme and after locating information sources. In Figure 3, the parts of the Tashi-Bot scheme are shown; a group of interactions are related that start from the TashiBot presentation and connect through the typed text or the selection made by the user.

Table 3. Comparison of tools for building Chatbots.

\begin{tabular}{|c|c|c|c|c|c|}
\hline Features & $\begin{array}{l}\text { Dialog- } \\
\text { Flow }\end{array}$ & Sap-Conversacional & IBM-WATSON & ChatFuel & ChatFuel \\
\hline $\begin{array}{l}\text { Free or paid- } \\
\text { for software }\end{array}$ & $\begin{array}{l}\text { Free and } \\
\text { paid-for }\end{array}$ & Free & Free anc & $\begin{array}{l}\text { Free and } \\
\text { paid-for }\end{array}$ & $\begin{array}{l}\text { Free or } \\
\text { paid-for } \\
\text { software }\end{array}$ \\
\hline $\begin{array}{l}\text { Platform (web, } \\
\text { mobile) }\end{array}$ & $\begin{array}{l}\text { Web - } \\
\text { Mobile }\end{array}$ & Web-Mobile & Web-Mobile & $\begin{array}{l}\text { Web - Mo- } \\
\quad \text { bile }\end{array}$ & Web \\
\hline $\begin{array}{l}\text { Learning curve } \\
\text { (ease of imple- } \\
\text { mentation) }\end{array}$ & e Easy & Easy & Easy & Easy & Easy \\
\hline $\begin{array}{l}\text { Number of im- } \\
\text { plementations } \\
\text { for chatbots }\end{array}$ & $\begin{array}{c}\text { - Si, KLM, } \\
\text { Domino } \\
\text { Pizza, }\end{array}$ & $\begin{array}{c}\text { More than } 100.000 \\
\text { Chatbots }\end{array}$ & Bank customers & N/A & $\begin{array}{l}\text { Several cli- } \\
\text { ents }\end{array}$ \\
\hline
\end{tabular}




\begin{tabular}{|c|c|c|c|c|c|}
\hline & $\begin{array}{l}\text { Ticket } \\
\text { master }\end{array}$ & & & & \\
\hline Methodology & $\begin{array}{l}\text { Not de- } \\
\text { fined }\end{array}$ & Not defined & Defined & Ader.so & Defined \\
\hline $\begin{array}{l}\text { Language sup- } \\
\text { port }\end{array}$ & Yes & Yes & Yes & No & Yes \\
\hline $\begin{array}{l}\text { Language sup- } \\
\text { port }\end{array}$ & Yes & Yes & Yes & No & Yes \\
\hline $\begin{array}{l}\text { Enterprise so- } \\
\text { lutions inte- } \\
\text { gration }\end{array}$ & Yes & Yes & Yes & No & Yes \\
\hline $\begin{array}{l}\text { Voice and text } \\
\text { support }\end{array}$ & $\begin{array}{l}\text { Voice } \\
\text { and text }\end{array}$ & Voice and text & Voice and text & Text & $\begin{array}{l}\text { Voice and } \\
\text { text }\end{array}$ \\
\hline $\begin{array}{l}\text { AI support } \\
(\mathrm{NLP})\end{array}$ & $\begin{array}{c}\text { Yes } \\
\text { (Google) }\end{array}$ & Yes & Yes (IBM) & No & Yes \\
\hline Schemes & No & No & Yes & No & Yes \\
\hline $\begin{array}{l}\text { Social net- } \\
\text { works }\end{array}$ & All & $\begin{array}{l}\text { Line, Messenger, } \\
\text { Skype, Telegram, } \\
\text { Twitter }\end{array}$ & N/A & Facebook & $\begin{array}{c}\text { Facebook, } \\
\text { WhatsApp } \\
\text { (payment), } \\
\text { Telegram, } \\
\text { Viber, Line, } \\
\text { Skype, } \\
\text { Slack. }\end{array}$ \\
\hline $\begin{array}{l}\text { Cost of profes- } \\
\text { sional plans }\end{array}$ & $\begin{array}{l}0.004 \\
\text { USD per } \\
\text { request }\end{array}$ & Free & $\begin{array}{c}\text { Ten messages free } \\
\text { per year }\end{array}$ & $\begin{array}{c}15 \text { USD } \\
\text { per month }\end{array}$ & $\begin{array}{c}30 \text { USD for } \\
10,000 \text { re- } \\
\text { quests }\end{array}$ \\
\hline
\end{tabular}

\subsection{Tashi-Bot implementation}

With SnatchBot, the Chatbot is created and then all the components are built through "interactions". Interactions are the communications between the user and the Bot and come in a wide variety of types to give the Bot functionality. The first interaction that is created is the "presentation", as shown in Figure 4. Here the application welcomes the user, introduces itself, and establishes the first open question, as well as offering a small menu of options so that the user can browse faster.

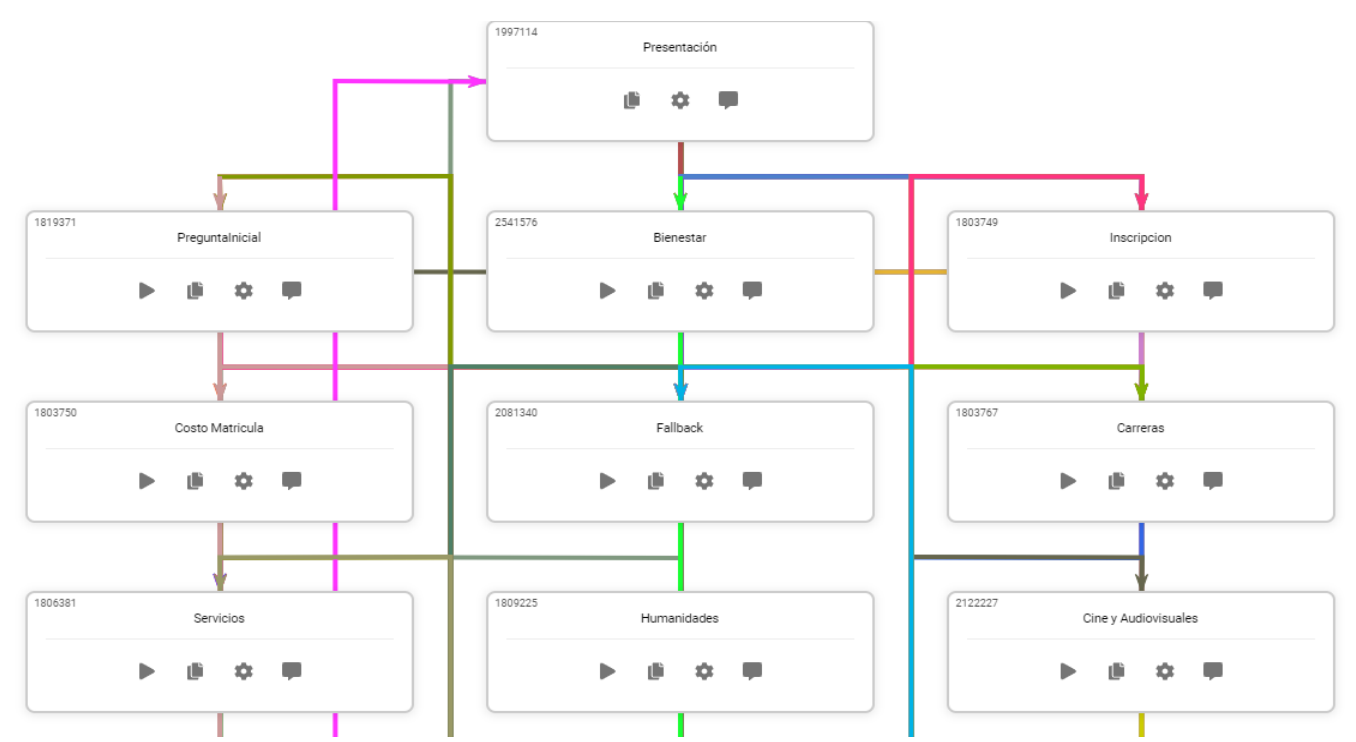

Figure 3. Tashi-Bot scheme. 
Each interaction has several components, such as the Bot Message, Cards (which are equivalent to quick access buttons), and Connections (which include fixed connections or NLP connections). The firsts are with training words or phrases that are directed to other interactions. NLP connections allow the creator to work with their own NLP model or with reusable pre-trained models.

The NLP models offered by the tool allow the creator to train the model with new intentions or entities. The intent in a sentence is the purpose or goal of the statement, for example, "I would like to buy a book." An entity in a sentence is a real-world object that can be named: a person, a place, an organization, or a time, among others. For example, in the phrase, "My sister traveled to Colombia," the entities are the sister (person) and Colombia (country).

The first interaction, Figure 4, triggers a set of Bot actions based on the user's response; these actions are communicating with another interaction, going somewhere to expand on the information, or simply asking again because the Bot does not understand the user.
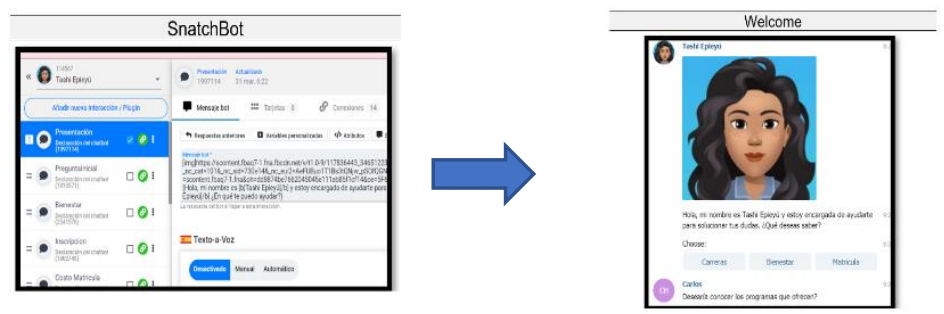

Bot response to Which programs are offered?
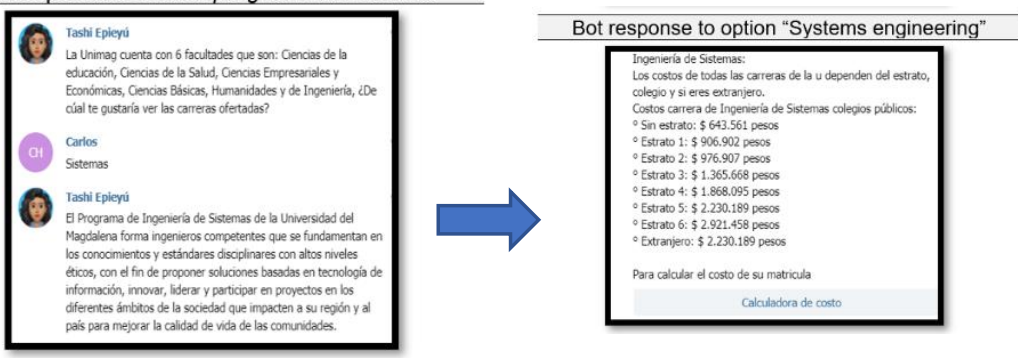

Bot response when not understanding context
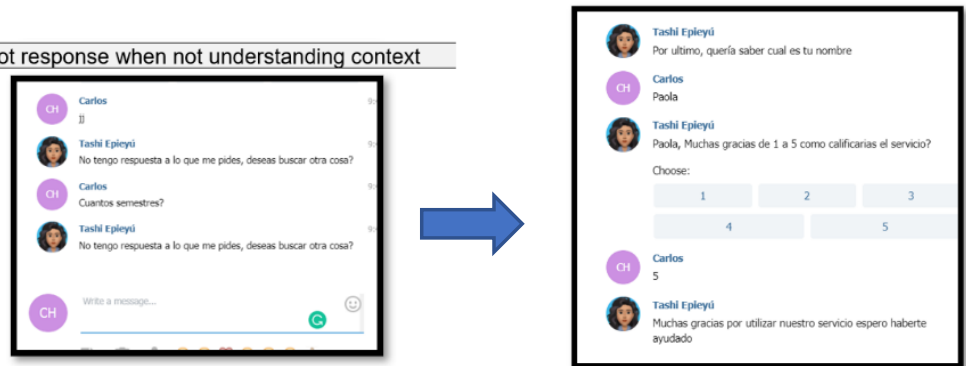

Figure 4. Tashi's first interaction.

The main interactions offered by the Bot are about well-being, initial questions, registration, tuition cost, fallback, majors, services, hours of operation, location, pre-goodbye, asking for a name, and requesting a rating. The Majors interaction offers a wide range of possible paths about each university major, tuition costs, and links to the university's web pages. The Fallback interaction is applied when the Bot does not understand the user and requests that they repeat their search. The Ask for Name and Ask for Rating interactions (Figure 5) are two interactions that connect with a previously trained NLP model that can identify a name and a grade in the user's response, to save it in permanent storage. 


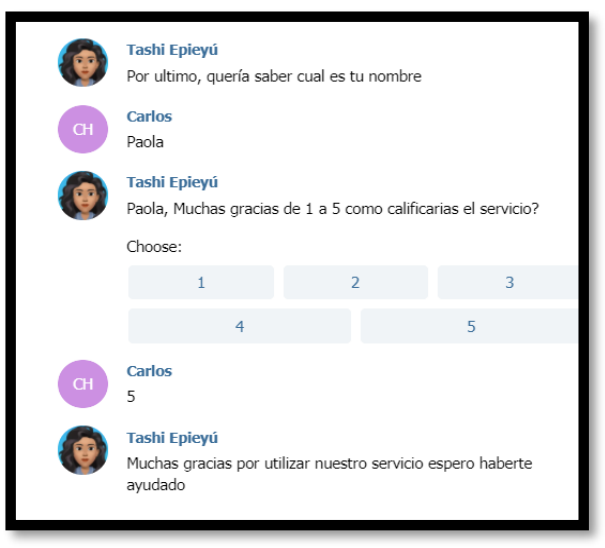

Figure 5. Request Name and Request Rating interaction.

Finally, each times a complete interaction is carried out, it is tested individually by the same tool (Figure 6) before being integrated into the Bot. Additionally, it is tested in the offline state before interacting with the user.

\subsection{Bot deployment}

After integrating and testing all the interactions, the Bot is configured in the tool by providing data such as the Bot profile, restart command, expiration time per session, and default error message, among others. A channel is then selected from among those offered by the tool; this is one of the various platforms that allow people to communicate around the world, including websites, email, SMS exchanges, and messaging applications, among others. One of the great features of the SnatchBot service is its omnichannel, which allows a built Chatbot to be deployed easily across all different channels. The channel selected for our beta test was Telegram [25] because this is a well-known social messaging network used in educational institutions and has a web alternative that works without mobile devices. Tashi-Bot (Figure 7) is currently available at https://web.telegram.org/\#/im?p=@TashiE Bot.

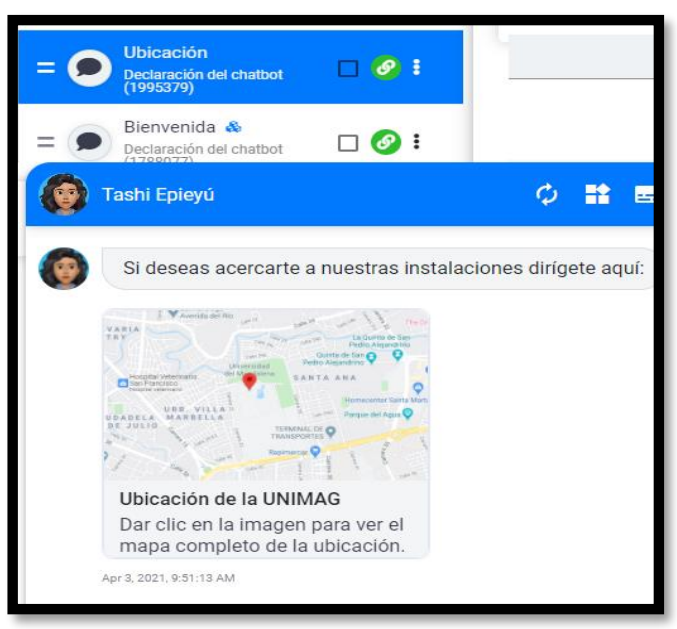

Figure 6. Interaction test. 


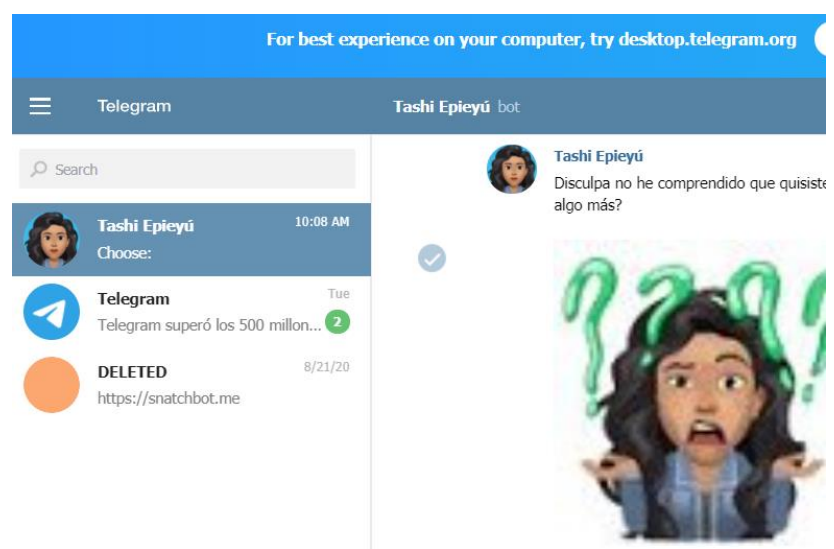

Figure 7. Deployment on Telegram channel.

Once Tashi-Bot was deployed on Telegram and using the same control group (90 students), the users were asked to interact with Tashi to inquire about different sources of information. Once the users were finished, a form was displayed to measure their satisfaction. The main questions on the form are shown in Table 4 . The answers given to the closed questions are shown in Figure 8.

Table 4. Questions to measure user satisfaction

\begin{tabular}{cc}
\hline Closed & Open \\
\hline 1. & Do you consider that your doubt was solved with our Chatbot? \\
2. & Would you recommend our Chatbot service to other people? \\
3. & Do you consider that the amount of text in the Chatbot responses is exces- \\
4. & Sive? \\
\hline
\end{tabular}



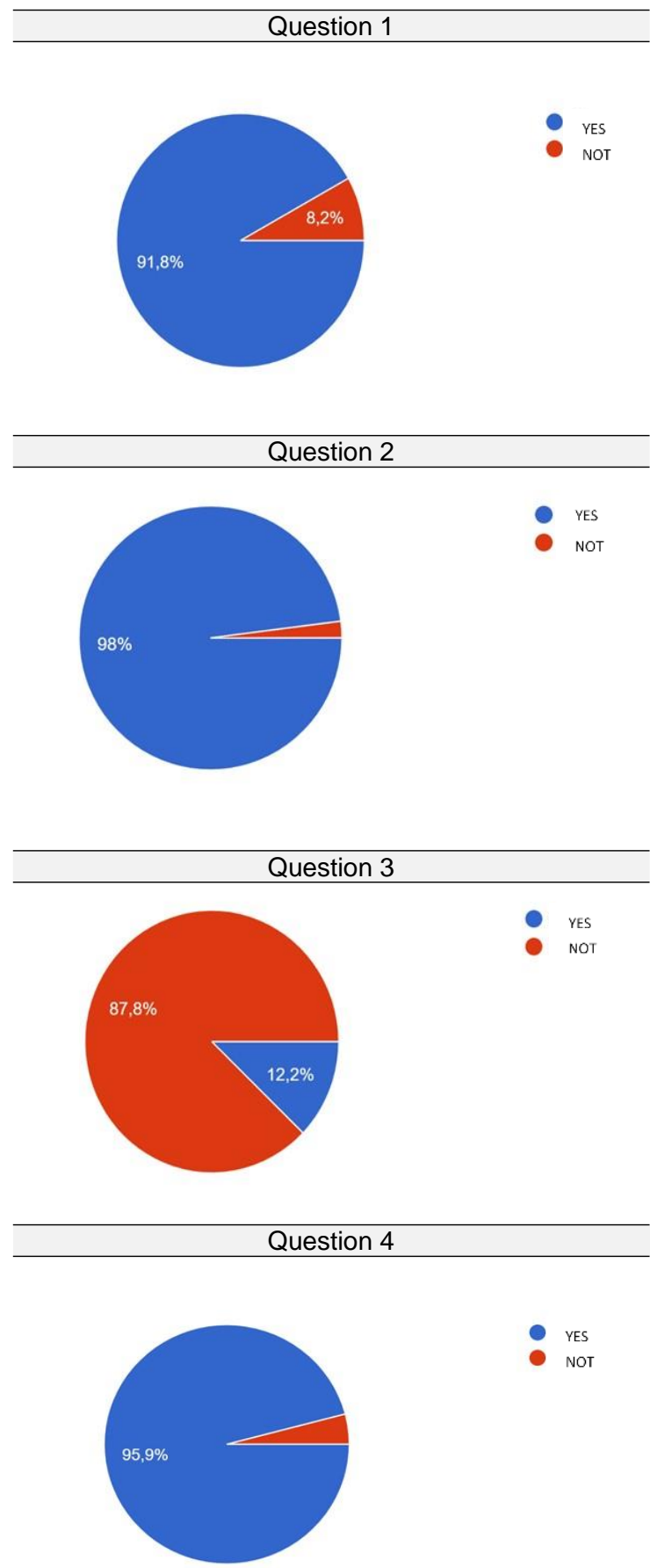

Figure 8. Telegram deployment channel.

The users' responses were overwhelmingly positive regarding the use of Tashi-Bot for the academic administration questions and answers provided. Of the 90 students surveyed, more than $92 \%$ were satisfied with the tool and would recommend it, while $12 \%$ considered that the amount of text should be reduced and combined with multimedia resources. Likewise, in the open questions, most of the users answered that more specific information was needed, together with information about the university. Additionally, the virtual assistant needed to be used for other specific instances, such as the library, admissions, laboratories, and help in the university's purchasing catalog. Finally, the suggestions presented include varying the Bot's responses, less text, more visual resources, improved visual quality and the offer of a guide to help to locate oneself within the institution. 


\section{Conclusions}

In this document, we present the design and implementation of a Chatbot system called Tashi-Bot that helps university students and aspiring students to obtain information about the educational and administrative processes of an educational institution. Tashi-Bot was created using the SnatchBot platform and was deployed on the Telegram social network.

For the creation of Tashi-Bot, a proprietary methodology was used after carrying out a study of the state of the art of previously built Chatbots. There were four phases: Analysis of needs and content, Chatbot design, Chatbot construction, and Test and deployment. The result of this process was a Chatbot that met the needs of the identified target population and prioritized the required information.

Based on user feedback, Tashi will be improved to provide more information processes, better visual quality, more multimedia resources, and deployment in different social networks. Additionally, more NLP models will be provided to give the Bot the ability to learn from user interaction. Finally, we will continue to use this technology in university education, particularly in teaching and learning processes.

Author Contributions: Conceptualization, H.C. and S.G.; methodology, H.C.; software H.C. and S.G.; validation, S.D., H.C. and S.G.; formal analysis, H.C.; investigation, S.G.; resources, S.D.; data curation, H.C.; writing-original draft preparation, S.D., H.C. and S.G.; writing-review and editing, S.D.; supervision, S.G.; project administration, S.D. All authors have read and agreed to the published version of the manuscript.

Funding: This research was funded by Magdalena University.

Acknowledgments: This publication is the result of the GIDSYC and its GLN seedbed from the University of Magdalena Colombia.

Institutional Review Board Statement: Not applicable.

Informed Consent Statement: Not applicable.

Conflicts of Interest: The authors declare no conflict of interest.

\section{Abbreviations}

The following abbreviations are used in this manuscript:

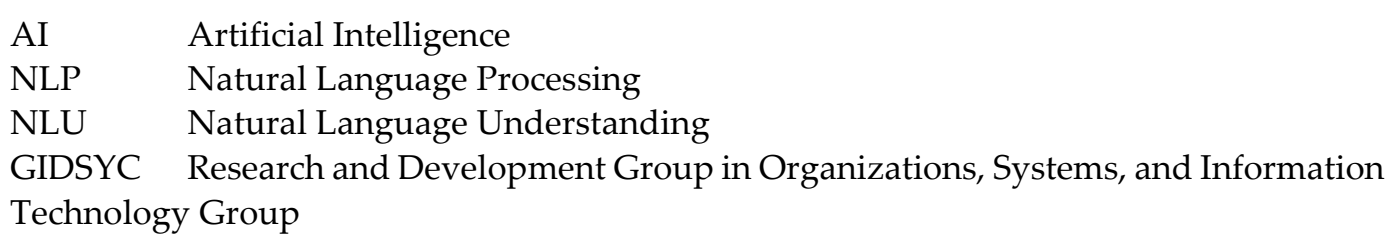

\section{References}

1. Negash, S.; Ryan, T.; Igbaria, M. Quality and effectiveness in Web-based customer support systems. Inf. Manag. 2003, 40, 757-768.

2. Henríquez, C.; Guzmán, J. Extracción de información desde la web para identificar acciones de un modelo de dominio en planificación automática. Ingeniare. 2015, 23, 439-448.

3. Henríquez, C.; Buelvas, E. AspectSA: Unsupervised system for aspect based sentiment analysis in Spanish. Rev. Prospect. 2019, 87-95.

4. Liddy, E. Natural language processing. In Encyclopedia of Library and Information Science; Marcel Decker, Inc.: New York, NY, USA, 2001.

5. Ruan, S.; Willis, A.; X, Qianyao.; Davis, G.; Jiang, Brunskill, L.; Landay, J. Bookbuddy: Turning digital materials into interactive foreign language lessons through a voice chatbot. In Proceedings of the Sixth (2019) ACM Conference on Learning@ Scale; Chicago, IL, USA, 2019.

6. Sjöström, J.; Dahlin, M. Tutorbot: A Chatbot for Higher Education Practice. In Lecture Notes in Computer Science (including subseries Lecture Notes in Artificial Intelligence and Lecture Notes in Bioinformatics; Springer: 2020; Volume 12388, pp. 93-98. 
7. Serban, I.V.; Sankar, C.; Germain, M.; Zhang, S.; Lin, Z.; Subramanian, S.; Kim, T.; Pieper, M.; Chandar, S.; Ke, N.R.; Rajeshwar, S. A deep reinforcement learning chatbot. arXiv 2017 arXiv:1709.02349.

8. Wu, Y.; Wang, G.; Li, W.; Li, Z. Automatic chatbot knowledge acquisition from online forum via rough set and ensemble learning. In NPC '08: Proceedings of the 2008 IFIP International Conference on Network and Parallel Computing, Massachusetts, NW, USA, October 18-21 2008; pp. 242-246.

9. Okuda, T.; Shoda, S. AI-based chatbot service for financial industry. Fujitsu Sci. Tech. J., 2018, 54, pp. 4-8.

10. Xu, A.; Liu, Z.; Guo, Y.; Sinha, V.; Akkiraju, R. A new chatbot for customer service on social media. In Proceedings of the 2017 CHI conference on human factors in computing systems, 2017, pp. 3506-3510.

11. Ukpabi, D. C.; Aslam, B.; Karjaluoto, H. Chatbot adoption in tourism services: A conceptual exploration. In Robots, artificial intelligence, and service automation in travel, tourism and hospitality; Emerald Publishing Limited, 2019.

12. Smutny, P.; Schreiberova, P. Chatbots for learning: A review of educational chatbots for the Facebook Messenger. Comput. Educ., 2020, 151, pp. 103862.

13. Shawar, B. A.; Atwell, E. Chatbots: Are they really useful? In Ldv forum, 2007, 22, pp. 29-49.

14. Adamopoulou E.; Moussiades, L. An overview of chatbot technology. In IFIP International Conference on Artificial Intelligence Applications and Innovations; 2020, pp. 373-383.

15. Yang, S.; Evans, C. Opportunities and challenges in using AI chatbots in higher education. In Proceedings of the $20193 r d$ International Conference on Education and E-Learning; 2019, pp. 79-83.

16. Sandu, N.; Gide, E. Adoption of AI-Chatbots to enhance student learning experience in higher education in India. In 2019 18th International Conference on Information Technology Based Higher Education and Training (ITHET); 2019, pp. 1-5.

17. Pham, X.L.; Pham, T.; Nguyen, Q.M.; Nguyen, T.H.; Cao, T.T.H. Chatbot as an intelligent personal assistant for mobile language learning. In Proceedings of the 2018 2nd International Conference on Education and E-Learning, 2018, pp. 16-21.

18. Hien, H.T.; Cuong, P.-N.; Nam, L N. H.; Nhung, H.L.T.K.; Thang, L.D. Intelligent assistants in higher-education environments: the FIT-EBot, a chatbot for administrative and learning support. In Proceedings of the ninth international symposium on information and communication technology; 2018, pp. 69-76.

19. Sánchez-Díaz, X.; Ayala-Bastidas, G.; Fonseca-Ortiz, P.; Garrido, L. A knowledge-based methodology for building a conversational chatbot as an intelligent tutor. In Mexican International Conference on Artificial Intelligence; 2018, pp. 165-175.

20. López, A.; Sànchez-Ferreres, J; Carmona, J.; Padró, L. From process models to chatbots. In International Conference on Advanced Information Systems Engineering; 2019, pp. 383-398.

21. Kalia, A. K.; Telang, P. R.; Xiao, J.; Vukovic, M. Quark: a methodology to transform people-driven processes to chatbot services. In International Conference on Service-Oriented Computing; 2017, pp. 53-61.

22. Kim, M.; Seo, B.-G.; Park, D.-H. Development process for user needs-based chatbot: Focusing on design thinking methodology. J. Intell. Inf. Syst. 2019, 25, pp. 221-238.

23. DialogFlow. Available online: https://dialogflow.cloud.google.com/\#/login (accessed 3 ${ }^{\text {rd }}$, April, 2021).

24. Snatchbot. Available online: https://es.snatchbot.me https://es.snatchbot.me/ (accessed 30 ${ }^{\text {th }}$, March, 2021).

25. Telegram. Available online: https://web.telegram.org (accessed 3rd, April, 2021). 